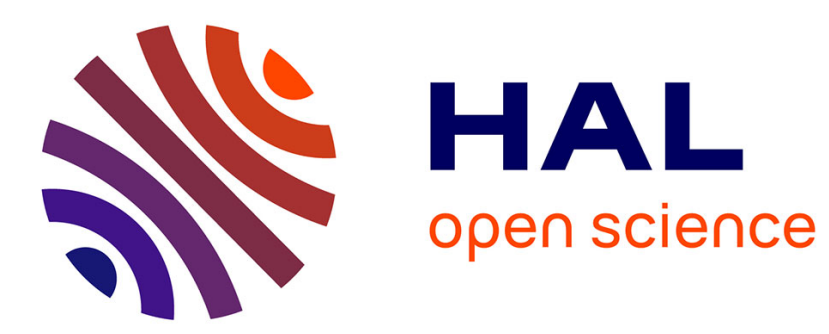

\title{
Effect of Invisible Exertions on Computed Tomography Radiologists in Saudi Hospitals
}

\author{
Saad Aldoihi, Omar Hammami
}

\section{To cite this version:}

Saad Aldoihi, Omar Hammami. Effect of Invisible Exertions on Computed Tomography Radiologists in Saudi Hospitals. 16th ACS/IEEE International Conference on Computer Systems and Applications (AICCSA 2019), Nov 2019, Abu Dhabi, United Arab Emirates. hal-02295402

\section{HAL Id: hal-02295402 \\ https://hal.science/hal-02295402}

Submitted on 24 Sep 2019

HAL is a multi-disciplinary open access archive for the deposit and dissemination of scientific research documents, whether they are published or not. The documents may come from teaching and research institutions in France or abroad, or from public or private research centers.
L'archive ouverte pluridisciplinaire HAL, est destinée au dépôt et à la diffusion de documents scientifiques de niveau recherche, publiés ou non, émanant des établissements d'enseignement et de recherche français ou étrangers, des laboratoires publics ou privés. 


\section{Effect of Invisible Exertions on Computed Tomography Radiologists in Saudi Hospitals}

\author{
Saad Aldoihi \\ Computer Science and Systems Engineering \\ ENSTA Paris, Institut Polytechnique de Paris \\ Palaiseau Cedex, France \\ aldoihi@ensta.fr
}

\author{
Omar Hammami \\ Computer Science and Systems Engineering \\ ENSTA Paris, Institut Polytechnique de Paris \\ Palaiseau Cedex, France \\ Hammami@ensta.fr
}

\begin{abstract}
Current radiology practices face extreme pressure on available resources with demands of multi-dimensional requirements. Technicians are at the center of a constant drive for optimal productivity and optimization with the minimal possible resources. This paper evaluates the invisible physical and mental exertions resulting from operating computed tomography (CT) scans by fifty-seven technicians surveyed following current radiology practices. Demographic characteristics were reviewed to evaluate differences across the study variables based on gender, level of education, years of experience, and working sector.

Index Terms - invisible exertions, Evaluation of invisible exertion, CT scan invisible exertion, CT scan overload effects
\end{abstract}

\section{INTRODUCTION}

The effects of physical and mental exertion on technicians working in radiology are overwhelming. Current radiology practice suffers from declining salaries, increasing workload, and workflow complexity [1]. Although a radiology work environment is categorized as shift work, disturbances in daily sleeping cycles are associated with physiological and behavioral effects as well as a loss of the rhythm entrainment [2]. Considerable fatigue and human error affect radiology practices with recent literature covering how diagnostic accuracy is compromised after long working hours [4][5][6][3] [7]. Under financial pressure, radiologists' practices are adopting a faster and more agile productivity style to accommodate larger workloads. Radiologists are now more likely to increase their interpretation error by $26.6 \%$ as opposed to $10 \%$ under average working speeds [8].

Radiology technicians today experience extreme pressure from many invisible exertion constraints, such as safety requirements, ethical practices, productivity and optimization requirements, system and technology requirements, and industry best practice adaptations. Regardless of the industry, most new requirements are driven by increasing safety [9]. Technicians are expected to facilitate all requirements while retaining the integrity of daily tasks. CT scan working conditions are categorized into the following themes:

- Dim lighting

- Small and confined control rooms

- Safety standards and practices

- Facilitating Technology

This study evaluates existing invisible physical and mental exertions experienced during CT scan operation and identifies demographic differences among the study participants, such as gender, age, years of experience, and working sector.

Furthermore, the study explores the type of invisible exertion as physical or mental. To the best of our knowledge, no previous research explored and evaluated these invisible exertion effects for CT technicians. As other researchers have not exploited the theme of this study, we expect this work can open a new arena of research for evaluating a variety of invisible exertions and their effects on working environments.

\section{DESCRIPTION OF THE PROBLEM}

The current state of hospitals demands a substantial amount of efficiency provided from a minimal amount of resources. So, radiologists today are working with multi-objective aims, such as safety and optimization of space and other resources, and exertions from various directions provide added pressure to radiologists. However, considerable pressure results from invisible sources. The working practice of CT scan radiologists demands proactivity and efficiency with daily operating routines that include helping bedridden patients move to the CT scan table, administrate the contrast media, and re-centering the position of the patient. Therefore, numerous such activities result as invisible exertions, which can be categorized as non-machine-related exertion. As hospital management teams strive to maximize productivity and optimize the intake of resources, identifying primary sources of invisible exertion is imperative to maximize productivity while minimizing human error.

In field observation, radiologists overcome invisible exertion through a variety of techniques and maneuvers. During a CT exam, extensive effort positioning the patient correctly on the CT table is required before the exam. Technicians are required to direct the patient to lay down on the CT table and ensure the patient is precisely centered. Often, after a technician has spent many hours of extensive operating exams, they may try to prevent invisible exertion by maneuvering the CT scanner instead of directly re-centering of each patient. So, without the need to configure a new exam for each patient, the technician modifies the previous exam for the new patient to avoid entering the exam room and re-centering the patient. Figure 1 and Figure2 show this repeated series functionality. Figure 3 summarizes the various exertions required during a 
CT scan, and this study highlights the impact of these actions on the operating technicians.

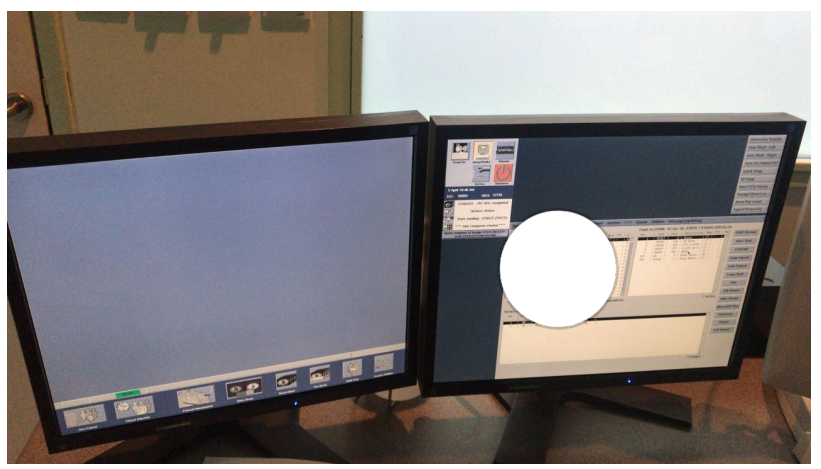

Fig. 1: Repeat Series

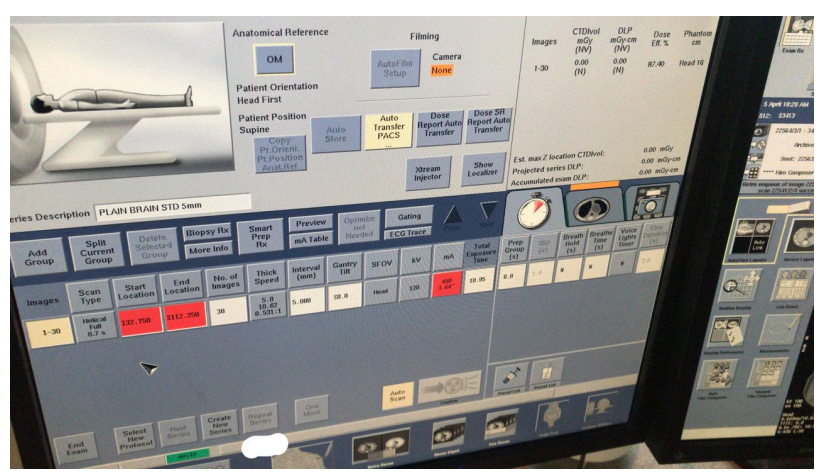

Fig. 2: Repeat Series

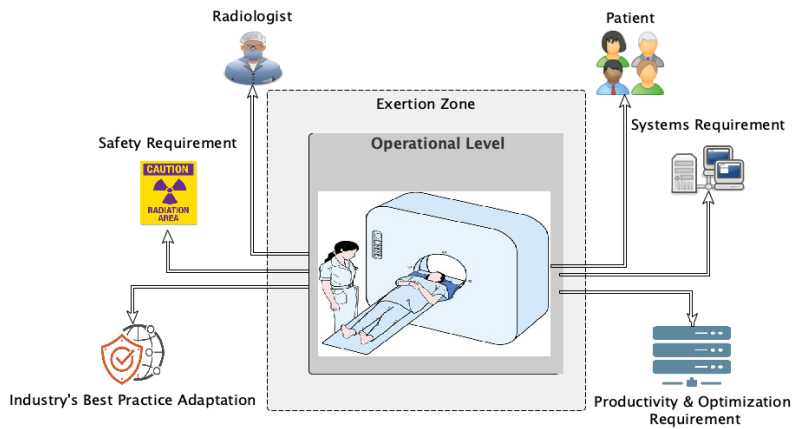

Fig. 3: Overview of the range of invisible exertions required by a CT technician.

\section{METHODS}

Eighteen hours of observational field visits were conducted at the Radiology Department in King Saud Medical City. This stage worked as a preliminary phase to collect and observe variables requirements. The purpose of the visits was to pinpoint the various sources of invisible physical and mental exertions. A questionnaire was also developed to measure invisible exertions in terms of the physical and mental aspects while operating a CT scanner.
Ethical approval was sought and approved by the Ministry of Health in Saudi Arabia after satisfying the legal requirements of the Ministry's Institutional Review Board. Also, ethical principles were maintained and preserved for confidentiality, anonymity, and the right to withdraw.

\section{A. Participant}

The study featured 57 radiology technologists who operate CT scans daily. The participants came from hospitals across all 13 regions. The genders comprised $50.9 \%$ male and $49.1 \%$ female with an age range from 20 to over 50 years. This range spread included $77.2 \%$ from 20 to 29 years, $15.8 \%$ from 30 to 39 years, $3.5 \%$ from 40 to 49 years old, and $3.5 \%$ over 50 years. Education comprises $3.5 \%$ as having earned a diploma, $86 \%$ with a bachelor's degree, and $10.5 \%$ with a master's degree. Years of experience consisted of $68.4 \%$ with 0 to 3 years, $8.8 \%$ with 4 to 7 years, $10.5 \%$ with 8 to 11 years, and $12.3 \%$ with more than 12 years. The working sectors included $87.7 \%$ in the public sector and $12.3 \%$ in the private sector.

\section{B. Procedure}

Following the initial on-site observations of CT operations, a survey consisting of two parts was developed to measure the invisible physical and mental exertions experienced while operating the CT scanner. The first part collected participant demographic characteristics, as reported in the previous section, and the second included participant responses for two invisible exertion measurements. A volunteer was recruited to visit the hospitals and offer a paper-based questionnaire. In addition, an electronic version of the questionnaire was developed and sent to the participants.

\section{Measurement}

The objective is to measure the physical and mental dimensions of invisible exertion. Table 1 describes these two dimensions each with three associated measurement attributes.

TABLE I: DIMENSION MEASUREMENT

\begin{tabular}{|l|l|}
\hline Exertion Dimension & Measurement \\
\hline \multirow{4}{*}{ Physical } & $\begin{array}{l}\text { Transfer a Bedridden patient from a hospital bed } \\
\text { onto a CT table }\end{array}$ \\
\cline { 2 - 2 } & $\begin{array}{l}\text { Prepare the examination room for receiving next } \\
\text { patient }\end{array}$ \\
\cline { 2 - 2 } & Prepare and administrate for contrast media \\
\hline \multirow{3}{*}{ Mental } & working in an understaffed environment \\
\cline { 2 - 2 } & the department needs more CT Scan machine \\
\cline { 2 - 2 } & the management targets are unreasonable \\
\hline
\end{tabular}

\section{RESULTS}

\section{A. Gender}

1) Invisible Physcial Exertion: Male respondents ( $\mathrm{Mdn}=$ 25.46) did not appear to differ from female (Mdn = 32.41) in the amount of transferring bedridden patients from a hospital bed onto a CT table $(\mathrm{U}=307)$. However, males $(\mathrm{Mdn}=$ 24.84) did significantly differ from females $(\mathrm{Mdn}=33.02)$ in preparing the examination room for the next patient ( $\mathrm{U}$ $=289.5, \mathrm{z}=-2.47, \mathrm{p}=0.013)$. Males $(\mathrm{Mdn}=24.62)$ also 
significantly differed from females $(\mathrm{Mdn}=33.22)$ in preparing and administering the contrast media for patients $(\mathrm{U}=283.5$, $\mathrm{z}=-2.35, \mathrm{p}=0.019$ ). Figure 4 and 5 provide box plots for these differing variables.

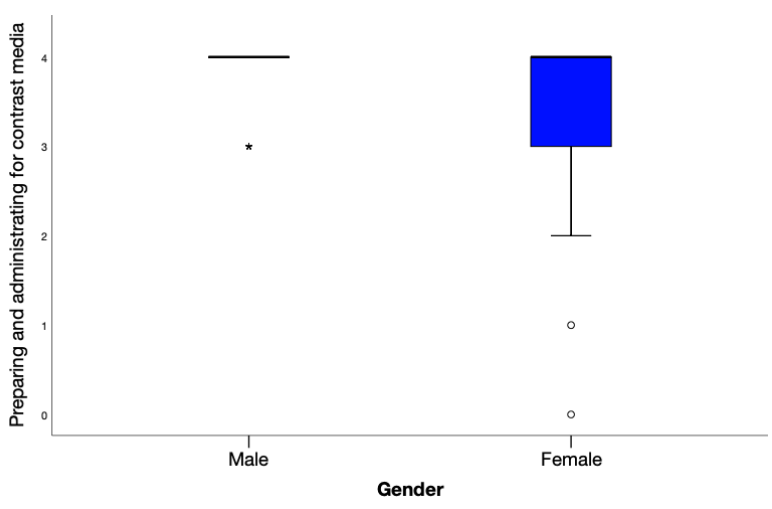

Fig. 4: Gender difference in preparing and administering the contrast media.

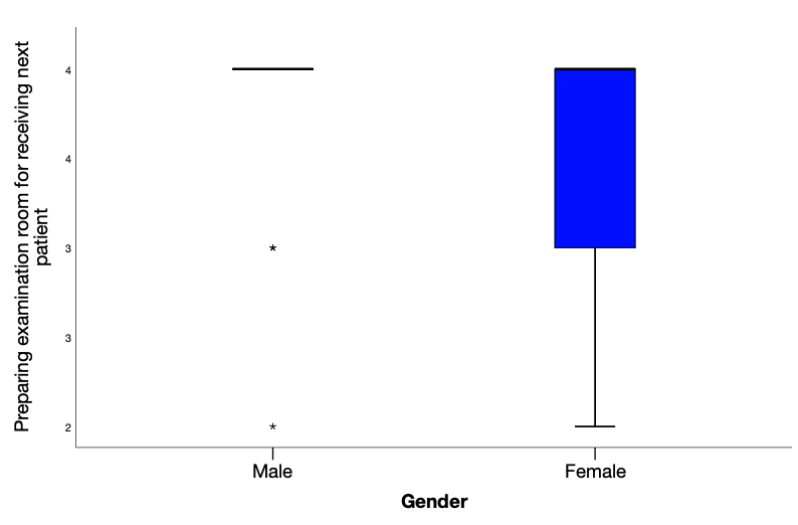

Fig. 5: Gender difference in preparing the exam room for the next patient.

2) Invisable Mental Exertion: A Mann Whitney test shows no difference between the males and females across all invisible mental variables.

\section{B. Age}

A Kruskal-Wallis test evaluated differences across the invisible physical and mental variables, and no significant differences were identified based on age groups

\section{Level of Education}

A Kruskal-Wallis test evaluated differences between three educational levels (diploma, bachelor's, and master's) regarding the participants helping transfer bedridden patients from a hospital bed onto the CT table. The test was significant $\mathrm{H} \mathrm{(2,}$ $\mathrm{N}=57)=7.91, \mathrm{p}=.01$.

Follow-up tests were performed to examine pairwise differences among these education group to control for type I errors using the Bonferroni approach. The results of these

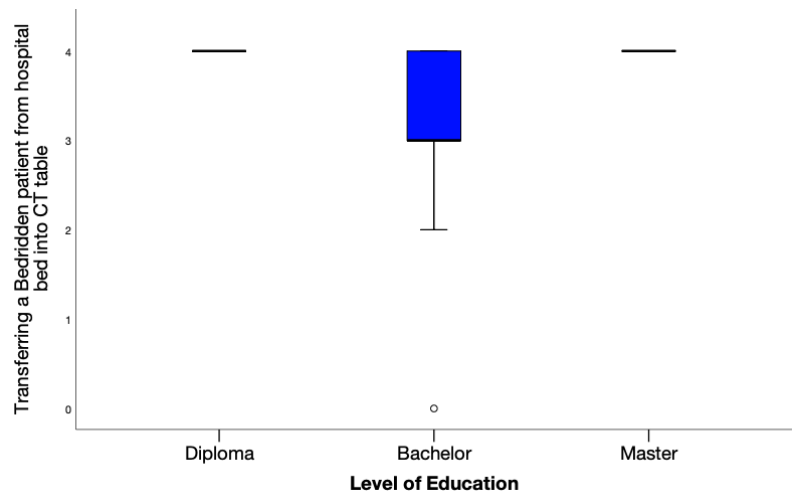

Fig. 6: The differences based on the level of education.

tests indicate a significant difference between bachelor's and master's degrees as illustrated in Figure 6.

Additionally, the other invisible physical and mental variables do not appear to differ based on the level of education.

\section{Years Of Expereince}

A Kruskal-Wallis test was conducted to evaluate the difference between the groups with similar years of experience ( 0 to 3,4 to 7,8 to 11 years, and more than 12 years) on working in an understaffed environment. The test resulted in a significant $\mathrm{H}(3, \mathrm{~N}=57)=9.23, \mathrm{p}=.02$.

Follow-up tests were performed to examine the pairwise differences among these groups to control for type I errors across the tests using the Bonferroni approach. The results of these tests indicate significant differences between the 0 to 3 and 4 to 7 years groups and between the 0 to 3 years and more than 12 years groups as are illustrated in Figure 7.

Additional tests were conducted on the other invisible physical and mental variables with no differences identified.

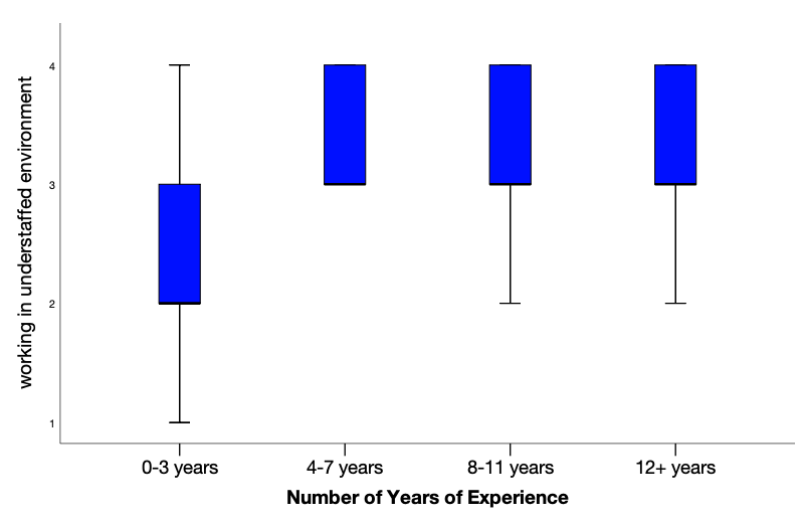

Fig. 7: Differences based on years of experience.

Additional tests were conducted on all invisible physical and mental variables and no differences were found.

\section{E. Working Sector}

The public sector technicians $(\mathrm{Mdn}=31.15)$ appeared to differ from the private sector $(\mathrm{Mdn}=13.64)$ in the response 
to the department needs more CT scan machines $(\mathrm{U}=67.5, \mathrm{z}$ $=-2.7, \mathrm{p}=.007$ ) as is illustrated in Figure 8 .

Additional tests were conducted on the other invisible physical and mental variables with no differences found.

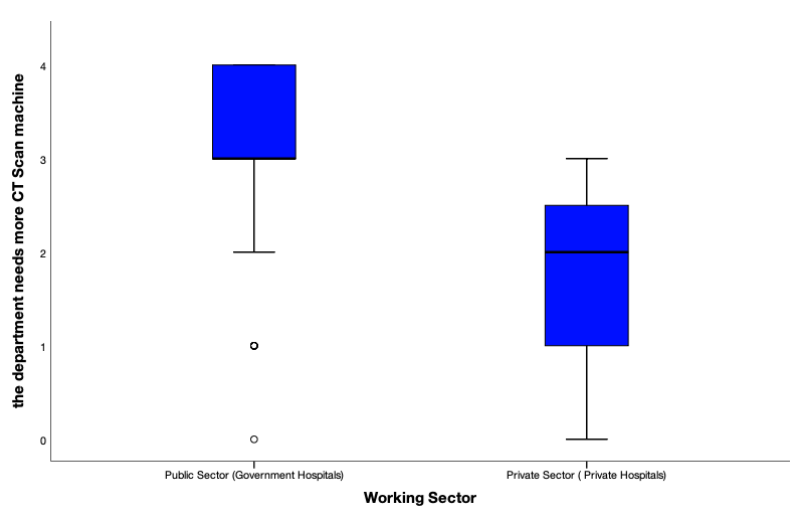

Fig. 8: Differences based on working sector.

Additional tests were conducted on all invisible physical and mental variables and no differences were found.

\section{CONCLUSION}

Radiology practices are impacted by many challenges that eventually require more exertion on the operators. The current standards in practice are categorized to drive for more efficiency in terms of consuming resources as they try to maximize productivity and optimization. Many requirements have been added to the processes of radiology, such as safety and ethics, to compromise a minimum for industry best practice. These requirements now reflect on the working load of the technicians and add complexity to the overall process. This study identifies this additional exertion that affects the technician as is experienced through invisible exertion.

\section{ACKNOWLEDGMENT}

The authors thank the Ministry of Health of Saudi Arabia for granting ethical approval and access to its facilities and employees. Special thanks go to Khaled Mohammed Al-Moadi for proving the images presented in this study.

\section{REFERENCES}

[1] Forman, Howard P., et al. "Masters of radiology panel discussion: hyperefficient radiology-can we maintain the pace?." American Journal of Roentgenology 199.4 (2012): 838-843.

[2] Berger, Ann M., and Barbara B. Hobbs. "Impact of shift work on the health and safety of nurses and patients." Clinical journal of oncology nursing 10.4 (2006).

[3] Krupinski, Elizabeth A., and Kevin S. Berbaum. "Measurement of visual strain in radiologists." Academic radiology 16.8 (2009): 947-950.

[4] Krupinski, Elizabeth A., et al. "Long radiology workdays reduce detection and accommodation accuracy." Journal of the American College of Radiology 7.9 (2010): 698-704.

[5] Krupinski, Elizabeth A., et al. "Do long radiology workdays affect nodule detection in dynamic CT interpretation?." Journal of the American College of Radiology 9.3 (2012): 191-198.

[6] Krupinski, Elizabeth A., et al. "The impact of fatigue on satisfaction of search in chest radiography." Academic radiology 24.9 (2017): 10581063.
[7] Taylor-Phillips, Sian, et al. "Retrospective review of the drop in observer detection performance over time in lesion-enriched experimental studies." Journal of digital imaging 28.1 (2015): 32-40.

[8] Sokolovskaya, Evgeniya, et al. "The effect of faster reporting speed for imaging studies on the number of misses and interpretation errors: a pilot study." Journal of the American College of Radiology 12.7 (2015): 683688.

[9] Miller, Cindy A. "Lessons from Another Industry: Aviation, Usability, and Medical Device Design.” Biomedical instrumentation and technology 47.s2 (2013): 40-44. 